\title{
Retention and Attrition of Students in Higher Education: Challenges in Modern Times to What Works
}

\author{
Marguerite Maher $^{1} \&$ Helen Macallister ${ }^{1}$ \\ ${ }^{1}$ School of Education, University of Notre Dame, Australia \\ Correspondence: Marguerite Maher, School of Education, University of Notre Dame Australia, PO Box 944, \\ Broadway, NSW 2007, Australia. Tel: 61-2-8204-4200. E-mail: marguerite.maher@nd.edu.au
}

Received: February 28, 2013

Accepted: March 18, 2013 Online Published: March 25, 2013

doi:10.5539/hes.v3n2p62

URL: http://dx.doi.org/10.5539/hes.v3n2p62

\begin{abstract}
Retention and attrition rates in higher education have long been a focus of research. This paper presents findings of a single case study, undertaken in a School of Education, which identify important strategies that have led to attrition of five to eight per cent, compared with 18 per cent cross the education sector in Australia (Department of Education, Science and Training, 2004). Findings include: individual admissions interviews, funding of an Associate Dean Pastoral Care, course coordinators providing continuity of support, easy access for students to academic staff, well-supported, extended professional experience, senior staff lecturing undergraduates, congruence between co-curricular supports and the educational framework, and comprehensive mentoring of new students. Finally, sustainability of these strategies in modern times is discussed.
\end{abstract}

Keywords: retention, attrition, initial teacher education, Australia, institutional initiatives

\section{Introduction}

This paper discusses the attrition rates from teacher education courses within the context of attrition in higher education generally and considers resultant detrimental effects on two levels: at a personal level to both students and staff, and at an institutional level. Comparisons are made between Australia where the current study took place, and other countries; lessons learned and successful mentoring strategies nationally and internationally are critiqued. This paper reports the findings from one small-scale single case study which sought to identify which specific pastoral care and course-design strategies, leading to retention of students, were noted as valuable by participants. These have seen one university achieve significantly lower attrition rates than those found across the sector. Elements are summarised that have been embedded at an institutional level resulting in these trends and challenges to their sustainability are discussed, given that most universities these days need to make cost-cutting decisions.

\subsection{Background}

An Australian Government Department of Education, Science and Training (2004) report, providing an overview of Higher Education attrition rates, notes that the '(attrition) rate for all domestic commencing undergraduate students was $21.2 \%$ compared to $18.0 \%$ for all international students' (p. 3). The data in this report show general consistency of attrition within each institution since 1994. These attrition rates are lower than those reported across students in the Organization for Economic Cooperation and Development (OECD) countries where one third of students withdraw from higher education without completing a qualification (OECD, 2008).

\subsection{Retention and Attrition Internationally}

Thus, high attrition rates are not specific to Australia. Cunningham (2007) describes similar statistics in the United Kingdom (UK) in teacher education. He highlights the importance of successful strategies leading to improved retention rates being systemically entrenched in 'the "architecture" of an institution' (p. 86). He notes the importance of an appropriate institutional ethos, the provision of physical resources for mentoring, induction, training and support for new staff who will be part of the mentoring team, providing clarity and consistency in student expectations, and evaluating the impact of mentoring.

Similarly, in the United States of America (USA), there has been in-depth consideration of reasons for student non-completion of higher education courses. Tinto (1993, 2000), working in the USA, developed a framework that considers students' pre-entry attributes and their own aspirations as possible predictors of success and 
retention. Tinto investigated how students' background attributes and their own goals impact on persistence, a key disposition which is likely to lead to successful completion.

A Norwegian study (Hovdhaugen, 2011) notes that the impact when students drop out of their courses amounts to a loss not only for the university concerned, but also for the individual and society. Specifically, there are negative implications for these students' self-esteem and efficacy (Cunningham, 2007). Additionally, employment prospects for those individuals become reduced (Torenbeek, Jansen, \& Hofman, 2010). These aspects hold true for students in Australia as well. Further to the social effects noted in the international studies, there are additional financial implications for Australian students since those students who do not complete have education debts with nothing to show for it; additionally government funding to universities to educate these students is wasted.

Reasons for student non-completion are complex. Student resources and their living arrangements play a role (Bozick, 2007). Student employment can contribute to dilution of application with a consequent lack of success leading to departure (Callender, 2008). One key factor in student success, which is not always achieved, is 'the fit between secondary education and university education' (Torenbeek, Jansen, \& Hofman, 2010, p. 659). This view is supported by Yorke and Longden (2008) whose research indicates that insufficient preparation for tertiary study causes some students to find it difficult to adjust to independent study and they are liable to withdraw early. These authors' research found that while it is assumed that on-campus attendance will automatically make students feel part of the community of learners, in fact first year students in large lectures can find the experience isolating and alienating.

For the student concerned, and for the university, it is important that as many as possible be supported to be successful. What, then, are current elements that seem to lead to greater success and retention of students?

\subsection{Strategies that Lead to Student Retention}

There are a number of studies that focus on strategies to enhance student engagement, which are seen as a subset of factors that will lead to greater success and, consequently, retention. Errey and Wood (2011), for example and providing an Australian perspective, identify pedagogy, class structure and nature of assignments, institutional factors and personal factors as key elements that increase or decrease engagement. Those that enhance student engagement lead to greater student satisfaction and success.

Activities and initiatives that promote students' feeling part of the community are important. Examples from the University of Western Sydney include ongoing refinements that build on existing orientation activities in their just-in-time and just-for-me principles ensuring peer and academic support for students (Gill, Ramjan, Koch, Dlugon, Andrew, \& Salamonson, 2011). Students need to feel valued and part of a supportive learning community, which extends beyond the lecture theatre. In their work, Noble and Henderson (2011) found that 'students' high quality interactions with peers and academic staff in an informal context are vital to academic success' (p. 79). Students involved in such interactions feel valued and, having a bond already established with lecturers, they are more apt to seek support, which enhances the likelihood of their success. This view is supported by a South Australian study which surveyed over 3000 first year students and found that having 'easy access to teaching staff outside of face-to-face teaching was seen as an important factor in success' (Scutter, Palmer, Luzeckyj, da Silva, \& Brinkworth, 2011, p. 8).

There has been substantial work undertaken at Queensland University of Technology on students' first year experience leading to success and retention. Kift, Nelson and Clarke (2010) have noted the importance of an 'intentional first year curriculum design that carefully scaffolds, mediates and supports first year learning' (p.11). This is achieved when professional and academic staff work together to support students and where co-curricular supports, such as peer mentors, dovetail with the educational framework of students' first year.

The discussion on factors affecting retention and attrition of higher education students, nationally and internationally, relate to all higher education courses, not pre-service teacher education specifically. This current study limited the lens to one School within the university as the researchers are particularly interested in the success of students in their school.

\subsection{The Role of Professional Experience}

Bringing the lens more closely to focus on elements more prominent in pre-service teacher education, we turn now to the role of professional experience as a factor impacting on student retention or attrition. For the purposes of this paper, we follow Fletcher, Patrick, Peach, Pocknee, Pretto, \& Webb (2009), authors of a large scale scoping study on work integrated learning (WIL), where they recognise WIL 'as an umbrella term used for a range of approaches and strategies that integrate theory with the practice of work within a purposefully designed 
curriculum' (Fletcher et al., 2009, p. v), clearly a pivotally important aspect in pre-service teacher education.

While universities might be 'seen as rarefied education institutions' (Smith, Brooks, Lichtenberg, McIlveen, Torjul, \& Tyler, 2009, p. 61) there is increasingly an expectation that qualifications will not only provide the theoretical underpinnings of a discipline, but also link to graduate destinations and prepare students for 'a smooth transition to practice' (Baguley, Beatty, \& Matthew, 2010, p. 10); future employers are simultaneously increasingly demanding enhanced graduate capabilities on their entry to the professions (Martin \& Fleming, 2010). The complex world of work within each profession becomes a focus during students' study (Daniel, 2010) with professional stakeholders progressively having input into the content of courses delivered by universities, thus ensuring students are provided with learning experiences that prepare them 'for the rigours of a rapidly changing global workplace' (Richardson, Kaider, Henschke, \& Jackling, 2009, p. 337).

Today in Australia, teaching practitioners undertake a four-year higher education degree to gain registration with their professional bodies but failure of Government to fund professional experience sufficiently has seen some institutions substantially reduce the amount of professional experience offered to pre-service teachers (Bloomfield, 2010). Because universities are under pressure financially, as Marginson notes, 'several Australian universities derive more than $20 \%$ of income from the (international) market, a high level of dependence' (p.17). Newcomers to the teaching professions are required to 'make fine discriminations in situations that are technically and socially complex' (Bates, 2008, p. 306). This is best accomplished in the theory to practice nexus that professional experience provides, but some universities have reduced the professional experience component because of the cost. At times there is also an over-reliance on the supervising teacher as financial constraints limit the support universities can offer to pre-service teachers whilst on professional experience in response to 'institutionally prescribed practices and outcomes' (Bloomfield, 2010, p. 221).

Additionally, as noted by Cherry (2005), there is a constant expansion of curricular knowledge and therefore additional pressure on students to master this increased volume of knowledge and, more importantly, apply it appropriately in practice. Professional experience promotes an alignment between learning outcomes and students' capacity to perform effectively. This capacity is best enhanced when progress is evaluated by themselves and by an expert (Briggs \& Tang, 2007).

In their large scale scoping study on WIL, Fletcher, et al., (2009) recommend (i) ensuring equity and access to WIL for all students, (ii) managing expectations and competing demands, (iii) ensuring worthwhile WIL experiences, and (vi) adequately resourcing WIL. In this paper, as one element, we discuss the successes and challenges of professional experience in pre-service teacher education in terms of these recommendations as students' ultimate success and self-efficacy is inextricably linked to the quality of support they experience from their supervising teachers (Bloomfield, 2010).

\subsection{In Summary}

Whilst not exhaustive, research and the literature reviewed in this paper provide insight into some of the most important reasons for students' early withdrawal from higher education and, more importantly, strategies that will enhance student success and retention. These are used as analyse, in the current study, elements that have seen one Australian university achieve a significantly lower attrition rate in its pre-service teacher education courses than is found across the sector. As each student is an individual, and their circumstances, thus, idiosyncratic, there are likely to be many more factors that come into play in individual circumstances than is within the scope of this paper to address. One limitation of this current study is that it was small-scale and could therefore not cover the entire range of possible factors impacting on students. Nevertheless, we have identified a number of themes from international and national studies, also highlighted by participants in the current study, which underscore the strategies that are worth considering at an institutional level.

\section{The Case}

This study took place on the Sydney campus of a multi-campus university in the School of Education which comprises 1400 students, 13 full-time staff and which offers three Education degrees: Early Childhood, Primary and Secondary. For the university pastoral care is very important because education is not only about the delivery of disciplinary content but developing character qualities in students. Pastoral care and an emphasis on providing professional excellence in its graduates, is embedded within the university philosophy. The Objects of the University are 'the provision of an excellent standard of ... training for the professions and pastoral care for its students' (Australian Government, 1989, p. 3). The Objects have played a key role in determining School culture, which is still developing as this campus only started in 2006 . These teacher education courses are not unique in aspiring to have strong support for their students; all universities do. But the university provides funding of roles within the staff that enhance the provision of pastoral care for students. Most teacher education 
courses also have a focus on the theory to practice nexus, but this university seems to be unique in funding extensive professional experience -31 weeks - in line with its Objects. This is a point of difference from many other universities and was noted by participants in the current study as a significant factor in student success.

\subsection{Research Questions}

There were three aspects to this study as we wanted participants to: a) evaluate the professional experience and their perceptions of its impact on student success b) identify what other aspects they considered important in contributing to the university's comparatively good retention rates, and c) provide advice on where improvements could be made.

\subsection{Methodology}

Evaluation of the four levels of support for students completing professional experience was an important part of the case study. These levels are, first, the university has developed strong partnerships with schools in Sydney, ensuring a worthwhile experience for students, noted by Fletcher et al. (2009), as key to successful WIL. In addition to the support of the classroom teacher, each student has the support either of a University Supervisor or a Head of Professional Practice (HoPP) within the school, a position funded by the university. This is a senior member of the school staff who oversees the student placement, observes lessons, provides regular feedback, and supports both the student and the classroom teacher if any problems arise. Students at schools which do not have a HoPP, have a designated University Supervisor who visits them three times during each 10 -week professional experience providing the same support the HoPP offers to students at their schools. Additionally, students in their second and third years attend eight two-hour sessions after school hours with a teaching skills specialist They are placed in groups of no more than 12 students where they work with a teaching skills specialist, an experienced practitioner who assists them to enhance their skills as reflective practitioners. Finally, there is support for students available from the Professional Experience Office at the university.

The evaluation was far wider than just the professional experience component, however. A single-case study methodology was utilised which enabled the researchers to explore what elements participants considered important in contributing to relatively lower attrition statistics - and how the university can potentially improve on this - while taking into consideration how these phenomena are influenced by the context itself (Baxter \& Jack, 2008). Ethics approval was gained and participants signed consent forms. Individual or group semi-structured interviews were held with participants as noted in Table 1, using the broad research questions.

\subsubsection{Data Collection}

Data were collected, in this single case study (Stake, 1995), by using the following methods:

- analysis of statistical data on attrition and retention rates for the last three years in Education pre-service degrees at this university compared with those across the sector

- individual interviews with senior faculty members who were employed at the foundation of the Sydney campus ( $\mathrm{n}=3)$, coded as SF1 to SF3 recruited via an email invitation to participate

- group interviews with current students $(\mathrm{n}=16)$, coded as CS1 to CS16 recruited via an email invitation to participate

- individual interviews with current staff members $(n=6)$, coded as ST1 to ST6 recruited via an email invitation to participate

- individual interviews with past graduates $(n=4)$, coded as GR1 to GR4 recruited via alumni society email to all education alumni

- individual interviews with principals of schools where students complete professional experience $(\mathrm{n}=15)$, coded as PR1 to PR15 recruited via an email invitation to participate

- group interviews with Heads of Professional Practice in schools ( $\mathrm{n}=11)$, coded as PP1 to PP11 recruited via an email invitation to participate

- Analysis of reasons provided by students who did withdraw.

\subsubsection{Sample Selection}

Sample sizes in the various participant groups differed. All senior faculty members who had been in the School of Education since its inception were interviewed $(n=3)$ as all indicated a willingness to contribute to the research. Current students $(\mathrm{n}=1400)$ self-selected who were prepared to contribute as part of group interviews $(\mathrm{n}=237)$. Random selection was used to group students into groups of five or six for group interviews depending on the times of their availability. After three group interviews involving 16 students, data saturation was reached. 
Of the 13 full-time staff, 10 indicated a willingness to participate. Individual interviews were held alternating between staff members who had been at the university for three years or fewer and those who had been at the university for more than three years. After interviewing three more recent appointees and three who had been longer at the university, data saturation was reached. Interviews with graduates took place after the group interviews with current students to see if there was variance of opinion from these participants who looked back on their experience with the wisdom of hindsight. After four interviews, it was evident that their views and those of current students were in accord. Schools which support students during professional experience $(\mathrm{n}=953)$ were grouped into those in high middle and low socio-economic areas and into sub-categories of whether they were in the Public, Catholic, or Independent systems. Random selection was used to select participants who were asked to participate. If a school principal declined, the next school on the list was approached. Similarly, with the HoPPs group, those from a variety of schools were participants in the current study.

It was decided not to predetermine sample size as the researchers were not looking for specific data, but wanted all participants' views to contribute to our understanding of the complexities of reasons for student success or early withdrawal from our courses. Therefore we worked from a principle of interviewing all participants in small groups, for example senior faculty where 100 per cent participated, and as many as necessary to reach data saturation.

\subsubsection{Data Analysis}

We were most interested in student views so started with two group interviews with them. Interpretive phenomenological analysis (Smith \& Osborne, 2003) was used to provide thematic coding in the analysis of the data. Within phenomenological epistemology, experience is given primacy "and is about understanding people's everyday experience of reality, in great detail, in order to gain an understanding of the phenomenon in question" (Braun \& Clarke, 2006, p.80) - in this case elements leading to high retention of education students. Therefore, first, strategies noted by students as important were clustered into themes, representing a level "of patterned response or meaning within the data set" (Braun \& Clarke, 2006, p. 82). Once we had these, other participant groups were interviewed in series and additional themes were noted as data were collected. Participants were interviewed until saturation was achieved with no additional aspects being raised by participants. Recurrent aspects noted by participants were the evidentiary excerpts used in this study for detailed analysis. The themes were then refined and analysed in relation to the review of the research and are reported in section 3 of this paper.

\subsubsection{Limitations}

This was a self-selected sample of participants; consequently it is possible that only the views of a certain type of person were portrayed. The wide range of participants and a relatively large sample, however, going beyond students to other stakeholders, provided a measure of triangulation. A recent survey conducted by an external body to the university, surveying a random selection of 1000 current students and alumni (across all disciplines, not education specifically), showed that to the statement 'I would recommend my university as the university of choice to friends and family wishing to study' 91 per cent answered 'strongly agree' on a five-point scale (SF1). It was not clear from interviews with students and alumni in the current study whether they represented the 91 or the nine per cent. With such a high proportion of students being positively disposed towards the university, it is possible that student and alumni participants in the current study do not represent the views of all education students. Nevertheless, it does not diminish the value of the views these participant categories articulate.

Another potential limitation is connected to the efficacy of staff and students who took part. It could be that they were more accepting of the strategies the university had implemented. Students and graduates indeed were speaking only from their single experience. Staff and senior faculty might have been more inclined to be supportive of their place of employment than to be critical. Providing a measure of balance, however, were the principals and HoPPs who encounter students from many universities in Sydney and have a good basis for comparison.

The group least effectively represented is those students who withdraw from a course. These early exit students could potentially best answer the question about how to improve on what the university is currently doing, but data from these students are limited. Students ceasing their studies are encouraged to undertake an exit interview with their course coordinator so they can be supported in this and also be counseled as to other opportunities they might like to consider. Almost invariably, though, these students who make up the attrition part of the university's statistics do not take up this offer. They prefer to fill in the form, where they are asked to provide a reason for their withdrawal. From a cohort that grew from approximately 800 to 1200 students between 2009 and 2011, only 40 students submitted withdrawal-from-course forms. Of these, 20 changed to another course, four 
moved intestate or overseas, five cited the financial imperative to work full-time, three cited health or family reasons such as having a baby, and two noted a potentially negative experience with the comments: 'lack of assistance and support with my medical condition and also unreliability with Lecturers' and 'At the moment, I don't feel like Uni is for me'. It would have been illuminating to talk with these students and gain deeper insight. From the attrition student cohort, 95 did not re-enrol, were noted as away without leave (AWOL), and never returned; consequently we have no insight into their reasons. Yet others apply for Leave of Absence (LOA) for one or two semesters, and some do not return. Between 2009 and 2011 there were 47 LOA students, and 12 returned. As with the AWOL students, we do not have any understanding of the lost LOA students' reasons for not continuing.

Despite the limitations, the findings produced some useful data.

\section{Findings and Discussion}

Table 1 provides a summary of the themes that emerged from analysis of the interviews and which strategies participants identified as important to student retention and success.

Table 1. Strategies noted by participants as significant in enhancing student retention

\begin{tabular}{ll}
\hline Strategies identified & By these participants \\
\hline Individual interview for each prospective student & Current students \\
& Graduates \\
& Current staff \\
Associate Dean Pastoral Care role & Senior faculty members \\
Course coordinators and student mentors & Current staff \\
& Current staff \\
& Current students \\
Senior staff teach first year students & Graduates \\
& Senior faculty members \\
Small classes & Current staff \\
& Current students \\
& Graduates \\
Four levels of support for students & Suring \\
professional experience & Participants from all categories \\
\hline
\end{tabular}

When pre-service teacher education was first offered in 2006 on the Sydney campus of a multi-campus university, staff members were aware of the attrition rates across the sector and senior leadership was determined to have as low an attrition rate as possible. One senior faculty member noted that 'having this as an explicit goal has had an impact on which strategies have been embraced' (SF2). Analysis of the data showed that the following strategies have contributed to attaining this goal.

\subsection{Individual Interview for Each Prospective Student}

Current students, graduates and current staff all highlighted the value of having an individual interview for each prospective student. Every prospective student is interviewed by an academic staff member; this serves multiple 
purposes. First, a student's reasons for choosing teaching as opposed to another degree can be ascertained. All students write a personal statement that supports their application and which serves as a starting point for the interview. As students are drawn out and encouraged to talk about their interests, their school and work experiences, and their experience with children, the lecturer 'can form an impression about the suitability of each student for teaching as a profession' (ST6). This university is committed to social justice and with prospective students evidence of community engagement is explored. This promotes the likelihood of there being a good fit between the student's expectations and that of the university, described by Torenbeek, Jansen, and Hofman (2010) as an important factor in later student retention and success. Second, a graduate comments, summing up the view of a large majority: 'It's great to have the interview - it made a good start for me. I felt really welcome' (GR4). This supports the view of Gill et al. (2011) that it is important that students have a good introduction to the university. At the interview staff members are welcoming which allows the student immediately to feel part of the community and valued as an individual. Furthermore, current staff agreed that the interview provided them with the opportunity to note potential problems a student may have mentioned which can be passed on to the course coordinators, who are responsible for the ongoing pastoral care of students in a specific course. Third, a current student summarises the view of many: 'because of the interview, I already knew someone. When I had trouble signing up for tutorials online I knew I had a port of call, you know, someone who I knew would help' (CS13). At the interview students are encouraged to meet with lecturers immediately if they should experience difficulties during their studies and it is emphasised that their course coordinator will be one of their lecturers so they will know whom to approach if they need assistance. The potential isolation that new students might feel (cf Yorke \& Longden, 2008) is ameliorated as the students have already met the receptionist who provides direction to supports available and the lecturer who interviewed them.

While current staff acknowledged the value of the individual interview as part of the enrolment process for both students and the university, they noted that there is no workload allocation to this practice and with increasing numbers of applicants they queried the sustainability of this strategy. The School is trialling using paid contract staff (long-standing tutors of the education units) to do some of the interviewing; it remains to be seen if the positives noted by students remain for them if the interview is conducted by a tutor rather than a lecturer.

\subsection{Associate Dean Pastoral Care}

The School of Education has two Associate Deans: one Academic and one Pastoral Care. Senior faculty members and current staff held that this reflects the 'importance the university attaches to the pastoral care of both students and staff (SF1). The Associate Dean Pastoral Care teaches an introductory unit to first year students thus establishing a relationship with them at the outset and, noted as important by Errey and Wood (2011), epitomising the commitment of the university to student success.

If this role is considered vital only by staff and senior faculty and not students, it begs the questions whether this is perhaps a role that could be sacrificed if costs have to be cut, given the current financial climate in which universities function.

\subsection{Mentors - Staff and Students}

Current staff, current students and graduates mentioned the important role the designated course coordinator plays. For example, ' $\ldots$ we got to know L... so well by the end, she was more like a friend' (GR1). The academic fulfilling this role, who also teaches first year students, gets to know and mentor students, providing support throughout the four years of their degree. One student provided an example:

A friend of mine had a crisis. Her husband was in an accident and she was, like, "oh, I'll have to pull out" but L... organised for her to get work online and extensions for assignments and all that. Deferred exam as well... I guess the relationship means lecturers pick up the warning signs, like, and help out' (CS8).

This role also serves to lessen the potential feeling of isolation a student might experience as noted by Yorke and Longden (2008). From a staff perspective, these support systems have positive outcomes: ' $\ldots$ if I have a student who misses a couple of tutorials and doesn't respond to my emails, I refer to the course coordinator who will call the student in or whatever to see what the problem is. I think that helps' (ST3).

Also contributing to the ethos of care recommended by Cunningham (2007) and highlighted by current students and graduates, is the extensive student mentoring system in operation. Both these participant groups noted the importance of this strategy for them when they started in first year. During orientation, each new student is 'buddied up' with a student mentor who is completing the same course, but who is in their third or fourth year, one of the co-curricular strategies identified by Kift, Nelson and Clarke (2010) as important but not sufficient in 
enhancing students' transition to university. These slightly older students undergo training so they are clear what their role as mentor encompasses and the buddy is an easy person to approach if a first year student should be reluctant to approach the Associate Dean Pastoral Care or a lecturer in the first instance. 'Mine was a life-saver in my first semester. Kept texting to check up on me. Was I okay? On track to get my first batch of assignments in? Took me for a coffee at the caf... I became a mentor myself later in fourth year' (GR2).

While the student-mentoring program looks to be systemically funded by the university, the funding of the course coordinator role is less secure. The staff members currently fulfilling these roles across teacher education courses have it factored into workload, but this is not reflected in their contracts or job descriptions. If the university were to insist on a full teaching load for these roles, it would certainly affect the level of support offered to students.

\subsection{Senior Staff Members Teach First Year Students}

Senior faculty members, current staff, current students and graduates all highlighted the importance of having experienced lecturers teaching first year students. 'The Dean taught us in our first semester. How cool is that?' (CS7). At this university, all academic staff members teach - from the Senior Deputy Vice Chancellor down. Senior staff members, such as the Dean of Education, not only teach and supervise post-graduate students, but s/he teaches at least one first year unit. This links to the view of Cunningham (2007) who notes the important part the ethos of a university plays in student retention. The commitment to providing excellent teaching to first year students is part of the ethos of this university and supports the findings of Kift, Nelson and Clarke (2010), that there needs to be alignment between the co-curricular support and course design and delivery.

With a strong emphasis on pastoral care and teaching, an area of relative weakness at this university is in the research arena. As the university grows in stature, however, there is an increasing number of higher degree by research students seeking enrolment. In the new Tertiary Education Quality Standards Agency (TEQSA) era, where only staff with a doctorate can supervise Master's students, it raises the question of whether the Dean, with supervisory capability, will be able to be freed up to continue to teach first years. The pursuit of quality in one area might compromise quality in another - the experience of first year students.

\subsection{Class Structure}

A conversation during a group interview with current students illustrates the important part class structure plays:

CS5: I think the way we have small tutes is important. Everyone can have a say. The lecturer gets to know us; must make it more likely we'll do well, surely?

CS8: Yeah. We get help. Can ask about assignments.

CS2: Also, I think we learn from each other. You know, with

presentations and so on.

Course design and class structure are notable factors in determining student access, engagement and success (Errey \& Wood, 2011; Kift, Nelson, \& Clarke, 2010). To ensure students do not feel isolated (Yorke \& Longden, 2008), lectures are restricted to 160 students. Where there are more than 160 students enrolled in a unit, the lecture is offered twice or three times; all students have face-to-face time with their lecturer. Furthermore, most lectures are an hour long, supplemented with two-hour tutorials where numbers are restricted to around 20 . This model provides students with the opportunity to experience quality interactions with peers and lecturers, noted as key factors by Noble and Henderson (2011) in student success and retention.

This sustainability of this strategy, as with several other elements discussed in this paper, is tenuous, dependent on university funding and prioritisation.

\subsection{Access to Staff}

All academic staff are expected to be on campus between 8.30 and 5 each week day. Different participants noted different aspects to this, highlighting a three-fold advantage. First, current staff noted that there is strong staff collegiality as staff know each other well which results in professional conversations, leading to improved practice; second, a senior faculty member noted that 'there is extensive collaboration between staff, therefore content of units is meaningfully integrated for students rather than being delivered in discreet silos' (SF2). Third, as described by a current student:

It is great that staff are readily available to students at all times. We all have different timetables, some of us work part-time, some have children so childcare issues. My friend at... (name deleted) University says her lecturers only put up on their doors a few hours they will see students and if the student can't 
be on campus those times, bad luck. Here we can always see them (CS11).

This accords with the findings of Scutter et al. (2011), who note that access to staff plays an important role in students feeling part of the community, in their willingness to seek assistance, and in enhancing the likelihood of their success.

\subsection{Professional Experience}

Participants from all categories noted the pivotal role played by professional experience in student motivation and retention. Students complete 31 weeks of professional experience during their pre-service teacher education. In the first year they complete a one week Classroom Immersion, which is largely an observation experience where students take note of the range of classroom interactions and reflect on these from the perspective of the professional role of the teacher and, as described by Daniel (2010), the complexity of the practice of teaching.

In both the second and third year of their course, students complete a 10-week block of professional experience, an entire term. Principals supported the length of the experience. 'It gives them (students) a real taste of the ebb and flow of a school term. They can be involved in all aspects, not just teaching' (PR6).

In their fourth year, students complete their final 10-week professional experience, in some instances called an internship. A graduate sums up the view of most, saying 'by then we are well able to explain not only what we do but why we do it. We are confident. I think it sets us up to have a good chance to do well in interviews, I mean, for jobs' (GR3). Being able to articulate clearly the theoretical underpinnings of their practice in schools, is noted by Fletcher et al. (2009) and Smith et al. (2009) as vital components for success.

Graduates note that they consider themselves 'advanced graduates, probably more so than students who have had less prac' (GR1) (cf Martin \& Fleming, 2010) with the capacity to make the fine discriminations (Bates, 2008) required to be an effective reflective practitioner. Graduates report a smooth transition to the profession (Baguley, Beatty \& Matthew, 2010) with the capacity to adapt to change noted as vital by Richardson et al. (2009). They have successfully integrated into three different schools and feel competent and confident on graduation. 'That's why I chose ........ (this) university. The amount of prac. I think that's why I got a job so easily too, at the end, at the school where I did my internship' (GR3).

\subsection{Support during Professional Experience}

All participant groups strongly supported the current model of support for students during their time in schools.

The following excerpt from a group interview with HoPPs highlights the positives for both confident students and those experiencing difficulty:

PP3: It's great that students get three independent visits from a supervisor or HoPP.

PP5: Yeah, when things are going well, they get another person's feedback and can improve further.

PP1: Yes, and they feel affirmed in what they are doing.

PP3: We get students from all over and I don't think any of the other unis have so many visits, do they?

PP2: No, and with the first visit early enough, in week 3, that means that

if a student is struggling there is time for them to come right by the end of the term.

Current students and graduates noted teaching skills specialist sessions as seminal in their development as effective reflective practitioners. 'I think the best thing I got from the sessions was the critical thinking thing. Before that I wasn't really sure what was and what wasn't' (CS12). This capacity to be effective reflective practitioners is enhanced as students explore self-evaluation, a practice recommended by Briggs and Tang (2007). This model enhances equity of access for all students, and assists all students to manage expectations and competing demands, described by Fletcher et al. (2009) as key components of successful WIL.

The extended professional experience placements, the resourcing needed to fund Teaching Skills Specialists, HoPPs and University Supervisors in addition to the supervising teacher, makes this university's model an expensive one, but participants were unanimous that benefits outweigh the cost. The sustainability of this model, however, is under threat from two perspectives. First, while the university is committed under its Objects to 
provide excellent training for the professions and is currently funding this level of support for students in extended professional experience, with the financial constraints all universities are under, this may change. Second, in New South Wales, the State with the highest population in Australia, the Minister for Education is questioning the amount and quality of teacher education and specifically the professional experience component, given the abundance of teachers at present. If a different funding model were to be introduced, this university's current professional experience model may well no longer be feasible.

\section{Outcomes}

The strategies described above, identified by participants as currently meeting student need, have been implemented since the Sydney campus was opened in 2006. These strategies have contributed to lower attrition rates, running between five and eight per cent as depicted in Table 2, than across the sector.

Table 2. Attrition and retention rates in undergraduate teacher education degrees 2008-2011

\begin{tabular}{ccccccc}
\hline Year & $\begin{array}{c}\text { Head } \\
\text { Count at } \\
\text { end Aug } \\
\text { each year }\end{array}$ & $\begin{array}{c}\text { EFTSL at } \\
\text { end Aug } \\
\text { each year }\end{array}$ & $\begin{array}{c}\text { Graduates } \\
\text { each year }\end{array}$ & $\begin{array}{c}\text { Continuing } \\
\text { in following } \\
\text { year }\end{array}$ & $\begin{array}{c}\text { Attrition } \\
\text { Rate }\end{array}$ & $\begin{array}{c}\text { Retention } \\
\text { Rate }\end{array}$ \\
\hline 2008 & 544 & 534.89 & 1 & 499 & $7 \%$ & $93 \%$ \\
2009 & 851 & 809.40 & 123 & 683 & $5 \%$ & $95 \%$ \\
2010 & 1045 & 954.79 & 165 & 793 & $8 \%$ & $92 \%$ \\
2011 & 1187 & 1117.60 & 159 & 928 & $8 \%$ & $92 \%$ \\
\hline
\end{tabular}

The first students enrolled on the Sydney campus in 2006, therefore only one, who received advanced standing, graduated in 2008 .

\subsection{Sustainability of Initiatives}

At the university described in this paper, the following aspects are embedded at an institutional level, part of 'the "architecture" of an institution' (Cunningham, 2007, p. 86):

- individual interviews required for all prospective students

- commitment to funding extensive periods of professional experience

- commitment to funding four levels of support for students on professional experience

- $\quad$ senior staff teaching first year students

- the appointment at Associate Dean level of someone to focus on pastoral care of students

- workload allocation to course coordinators for their pastoral care role

- $\quad$ all staff being on campus during weekday working hours.

As the university grows, however, and with competing priorities, it may become difficult to sustain some of these strategies. For example, interviewing of each prospective student is very time-consuming and does not currently factor into staff workload; with competing demands, it might not be possible to provide in-depth interviews, which are current practice. With increasing expectations that staff should be involved in research and scholarship, it might not be feasible to expect all staff to be on campus at all times. As the university grows and the number of post-graduate students increases, it might not be possible to have all senior staff teaching first year students.

The statistics speak for themselves; this study reinforces findings, noted in the literature, that mentoring and support strategies do lead to improved retention. However, this raises the issue, as noted in the conclusion below, of the key factor in the achievement of excellent mentoring - sufficient funding to universities to put this in place.

\section{Conclusion}

The strategies discussed in this paper appear to play an important role in reducing the attrition rate in pre-service teacher education courses. Clearly, questions remain around the sustainability of the strategies highlighted as valuable by participants in the current study. To the question of how the university could improve what it does, 
participants endorsed the status quo. It is here that data from those students who withdrew early would have been most useful; they would be best placed to advise on areas where they would have liked more support. Unfortunately these data are not comprehensive.

It will always be a balancing act to achieve excellent student support and the costs involved. The expectations on academic staff reported in this paper are great, including attendance at the university and time spent interviewing prospective students. These rely on goodwill alone as teaching workloads are high too when compared across the sector. So, while the university bears the financial costs aligned with four levels of support during professional experience, the other costs are borne by academic staff in other ways, such as limiting time to engage in research and scholarship.

The government in Australia is committed to increasing the number of citizens who hold a Bachelor degree, with a specific focus on people from low socioeconomic backgrounds or who are of Aboriginal and Torres Strait Islander descent. These students would, as evidenced in the current small-scale study, benefit from a similar multi-layered approach to support. For the authors of this paper, achieving the government targets is one thing; for them the increased social capital when these students are successful and the enormous damage done to self-esteem when they are not, are the drivers to continue to strive for multiple forms of student mentoring support.

\section{References}

Australian Government. (1989). The University of Notre Dame Australia Act. Retrieved from http://www.slp.wa.gov.au

Baguley, J., Beatty, J., \& Matthew, S. (2010). Analysing opportunities for technical skill develpment to inform curriculum design. Synergy, 30, 10-15.

Bates, M. (2008). Work-integrated curricula in university programs. Higher Education Research and Development, 27(4), 305-317. http://dx.doi.org/10.1080/07294360802406775

Baxter, P., \& Jack, S. (2008). Qualitative case study methodology: Study design and implementation for novice researchers. The Qualitative Report, 13(4), 544-559.

Bloomfield, D. (2010). Emotions and 'getting by': A pre-service teacher navigating professional experience. Asia-Pacific Journal of Teacher $\quad$ Education, $221-234$. http://dx.doi.org/10.1080/1359866X.2010.494.005

Bozick, R. (2007). Making it through the first year of college: The role of students' economic resources, employment, and living arrangements. Sociology of Education, 80(3), 261-285. http://dx.doi.org/10.1177/003804070708000304

Braun, V., \& Clarke, V. (2006). Using thematic analysis in psychology. Qualitative Research in Psychology, 3(2), 77-101. http://dx.doi.org/10.1191/1478088706qp063oa

Briggs, J., \& Tang, C. (2007). Teaching for quality learning at university (3rd ed.). Maidenhead, UK: McGraw Hill, Society for Research into Higher Education and Open University Press.

Callender, C. (2008). The impact of term-time employment on higher education students' academic attainment and achievement. Journal of Education Policy, 23(4), 359-377. http://dx.doi.org/10.1080/02680930801924490

Cherry, N. L. (2005). Preparing for practice in the age of complexity. Higher Education Research and Development, 24(4), 309-320. http://dx.doi.org/10.1080/07294360500284649

Cunningham, B. (2007). All the right features: Towards and architecture for mentoring trainee teachers in UK further education colleges. Journal of Education for Teaching, 33(1), 83-97. http://dx.doi.org/10.1080/02607470601098351

Daniel, R. (2010). Career development and creative arts students: An investigation into the effectiveness of career theory and WIL experiences on practice. Australian Journal of Career Development, 19(2), 14-22. http://dx.doi.org/10.1177/103841621001900203

Department of Education, Science and Training. (2004). Higher Education Attrition Rates 1994 to 2002: A brief overview. Canberra, ACT: Australian Government.

Errey, R., \& Wood, G. (2011). Lessons from a student engagement pilot study: Benefits for students and academics. Australian Universities Review, 53(1), 21-34. 
Fletcher, M., Patrick, C., Peach, D., Pocknee, C., Pretto, G., \& Webb, F. (2009). The WIL (Workplace Integrated Learning) report: A national scoping study. Brisbane: Queensland University of Technology.

Gill, B., Ramjan, L., Koch, J., Dlugon, E., Andrew, S., \& Salamonson, Y. (2011). A standardised orientation program for first year undergraduate students in the College of Health and Science at UWS: A practice report. The International Journal of the First Year in Higher Education, 2(1), 63-69. http://dx.doi.org/10.5204/intjfyhe.v2i1.48

Hovdhaugen, E. (2011). Do structured study programmes lead to lower rates of dropout and student transfer from university? Irish Educational Studies, 30(2), 237-251. http://dx.doi.org/10.1080/03323315.2011.569143

Kift, S., Nelson, K., \& Clarke, J. (2010). Transition pedagogy: A third generation approach to FYE - a case study of policy and practice for the higher education sector. The International Journal of the First Year in Higher Education, 1(1), 1-20. http://dx.doi.org/10.5204/intjfyhe.v1i1.13

Marginson, S. (2007). Global position and position taking: The case of Australia. Journal of Studies in International Education, 11(5), 5-32. http://dx.doi.org/10.1177/1028315306287530

Martin, A., \& Fleming, J. (2010). Cooperative education in outdoor education. Australian Journal of Outdoor Education, 14(1), 41-48.

Noble, K., \& Henderson, R. (2011). The promotion of 'character' and its relationship to retention in higher education. Australian Journal of Teacher Education, 36(3), 79-91. Retrieved from http://ro.ecu.edu.au/ajte/vol36/iss3/4

Organization for Economic Cooperation and Development (OECD). (2008). Education at a glance 2008: OECD indicators. Paris: Centre for Educational Research and Innovation, OECD.

Richardson, J., Kaider, F., Henschke, K., \& Jackling, B. (2009). A framework for assessing work integrated learning. Paper presented at the 32nd HERDSA annual conference.

Scutter, S. D., Palmer, E., Luzeckyj, A., da Silva, K. B., \& Brinkworth R. (2011). What do commencing undergraduate students expect from first year university? The International Journal of the First Year in Higher Education, 2(1), 8-20. http://dx.doi.org/10.5204/intjfyhe.v2i1.54

Smith, J. A., \& Osborne, M. (2003). Interpretive phenomenolgoical anaysis. In J. A. Smith (Ed.), Qualitative psychology: A practical guide to methods (pp. 51-80). London: Sage.

Smith, M., Brooks, S., Lichtenberg, A., McIlveen, P., Torjul, P., \& Tyler, J. (2009). Career development practice: Facilitating work-integrated learning in higher education. Australian Journal of Career Development, 18(2), 60-64. http://dx.doi.org/10.1177/103841620901800210

Stake, R. E. (1995). The art of case study research. Thousand Oaks, CA: Sage.

Tinto, V. (1993). Leaving college (2nd ed.). Chicago: University of Chicago Press.

Tinto, V. (2000). Linking learning and leaving: Exploring the role of the college classroom in student departure. In J. M. Braxton (Ed.), Reworking the student departure puzzle. Nashville: Vanderbilt University Press.

Torenbeek, M., Jansen, E., \& Hofman, A. (2010). The effect of the fit between secondary and university education on first-year student achievement. Studies in Higher Education, 35(6), 659-675. http://dx.doi.org/10.1080/03075070903222625

Yorke, M., \& Longden, B. (2008). The first-year experience of higher education in the UK: Final report of a project funded by the Higher Education Academy. York: Higher Education Academy. Retrieved March 20, 2012,

from http://www.heacademy.ac.uk/assets/documents/resources/publications/exchange/FYEFinalReport.pdf 